\title{
ENSAYOS
}




\section{CORRIENTES IDEOLOGICAS EN LA EDUCACION COMPARADA*}

Por: Erwin H. Epstein

La idea de que la escolaridad puede no ser totalmente invulnerable a la ideología, perturba profundamente al mundo académico. Se supone que la ciencia descubra la verdad -buscando retirar el velo del juicio subjetivo para lograr sabiduría, discernimiento y comprensión. Los métodos sistemáticos están cuidadosamente diseñados para lograr esta meta. Tomos enteros están dedicados solamente a fomentar la objetividad en procedimiento y a evitar la decepción ideológica. El temor de la ideología está bien justificado, puesto que una ciencia contaminada por las ideas del partidismo disminuye la actividad intelectual.

En la educación comparada debemos preocuparnos particularmente por los intrincamientos con la ideología. Los campos comparativos son peculiarmente vulnerables al estar expuestos a diversas orientaciones nacionales y a panoramas mundiales incompatibles. Además, la educación es el mecanismo mas perdurable de la sociedad para inculcar sistemas de opinión. Sin embargo, raramente hemos reconocido abiertamente la existencia de ideología en nuestras actividades, por mucho que luchemos contra metodologías competidoras. Bien sea por observar una etiqueta académica o debido a simple olvido, los letrados en el campo por lo general no han identificado explícitamente las raíces ideológicas de la orientación rival. A menos de que confrontemos abiertamente el problema de ideología, éste disfrazará la percepción y afectará el valor de nuestro trabajo.

Argumentaré que lo esencial de una teoría educativa -especialmente la dedicada a la política de la acción humana- no solamente lo que la teoría dice explícitamente, sino lo que omite decir o aquello cuyo contenido es de difícil reconocimiento. Demostraré también que lo que importa acerca de la metodología en la educación comparada no es solamente el procedimiento empleado en la investigación de un problema sino los juicios de valor que informan ese procedimiento. Finalmente, pretendo demostrar que el modelo principal que se ha utilizado para explicar el desarrollo de la educación comparada ha sido inadecuado, y que necesitamos dar cuenta más competentemente de las ideologías que han influido el desarrollo del campo.

\section{"Progreso" en el desarrollo de la Educación Comparada}

Ya es convencional en nuestro campo considerar que el desarrollo de la educación comparada ha progresado en etapas. Noah y Eckstein, cuyo influyente libro, Toward a Science of Comparative Education, nos recuerda la noción de progresión, -identifica tres amplias etapas metodológicas: la etapa 1a. se caracteriza como una empresa de recopilación de datos de naturaleza enciclopédica y algo indiscriminada; la etapa 2a., introducida por Michael Sadler y más notablemente promovida por Nicholas Hans e Isaac Kandel, hizo más énfasis en la explicación que en la descripción y procuro esa explicación en un estudio del contexto histórico y de la influencia de las fuerzas culturales, y la etapa

\footnotetext{
${ }^{*}$ Discurso presidencial ante la Asociación Internacional de Educación Comparada. Agradezco los útiles comentarios de C. Arnold Anderson, Sandra Ben-Zeev, John Craig, Gail Kelly, y de los estudiantes y de la plana mayor del seminario de Educación Comparada de la primavera de 1982 en la Universidad de Chicago.
} 
3a., considerada en la actualidad como la metodología de la línea central consiste en la aplicación de métodos científicos sociales empíricos y en un autoconvencimiento de los procedimientos $^{1}$. Kazamias, aun cuando difiere en parte de la forma en que Noah y Eckstein conciben el desarrollo del campo, no obstante distingue entre el enfoque "antiguo" y "nuevo" hacia la metodología en la educación comparada. Kazamias aduce que los enfoques antiguos eran descriptivos y prescriptivos y que mezclaban indiscriminadamente "lo que es" en la educación con "lo que debería ser". Por contraste, los nuevos métodos -a los que Kazamias se refiere como enfoques filosóficos, funcionales y problemáticos - tienden a ser microcósmicos y más "científicos"2. Más recientemente Kelly y Altbach, después de reconocer los enfoques citados por otros, reportan el surgimiento de lo que ahora han llegado a ser las "nuevas" perspectivas metodológicas en la educación comparada -enfoques etnográficos y sistemas que utilizan conceptos tales como neocolonialismo, análisis del sistema mundial y teoría de dependencia para argumentar que los sistemas educativos están directamente afectados por las corrientes internacionales y que los sistemas escolares racionales y las relaciones entre la escuela y la nación ya no son asunto de análisis ${ }^{3}$ - Por mucho que varíen estas descripciones del campo, todas mantienen la noción de progreso.

Por muy conveniente que haya sido considerar el desarrollo de la educación comparada como una evolución por etapas, esta perspectiva ha creado confusión sobre la utilidad y valor relativo de los enfoques alternativos. Con la maduración de la educación comparada deberíamos poder ver cómo cada etapa sucesiva ha representado un incremento de mayor objetividad y claridad en el estudio de la educación. Por el contrario encontramos que la literatura contemporánea no es clara con respecto a la metodología apropiada en la educación comparada. ¿Es más probable que el estudiante de educación comparada en la década del 80 se sienta más seguro de la idoneidad u objetividad de una metodología seleccionada que lo que se sentía el estudiante de la década del 50? Como producto de los años 60 , me sentía mucho más seguro acerca de lo que era una "buena" metodología en esos años formativos que lo que me siento en la actualidad. Los métodos continúan reclamando un progreso constante para nuestro campo medido por el reemplazo de los "antiguos" enfoques ideológicamente propensos a métodos objetivos cada vez más "nuevos". Sostengo que esas afirmaciones no tienen fundamento. Por mucho que hayamos mejorado nuestra aplicación de herramientas tecnológicas y cuantitativas al análisis de problemas educacionales, no hemos progresado ni un solo paso para llegar a ser observadores desinteresados, ideológicamente imparciales de las relaciones escuela-sociedad.

Las raíces ideológicas de la investigación académica fueron anteriormente identificadas, principalmente por Paulston, quien contempla las tendencias ideológicas que caracterizan los enfoques teóricos principales como no necesariamente incompatibles ${ }^{4}$. Sugiere inclusive que la investigación comparativa podría apartarse críticamente de estas orientaciones compensadoras aun cuando la descripción de Paulston de la investigación comparativa es única en cuanto que reconoce la ideología y elude la idea de desarrollo progresivo, subestima la irreconciliabilidad de las ideologías

\footnotetext{
${ }^{1}$ Harold J. Noah $y$ Max A. Eckstein, Toward a Seience of Comparative Education (New York: Macmillan, 1969), pag. 65.

2 Andreas M. Kazamias, "Some Old and New Approaches to Methodology in Comparative Education", Comparative education Review 5 (Octubre 1961): 90-96.

${ }^{3}$ Gail P. Kelly y Pbilip G. Altbach. "Comparative Education: A Field in Transition", en international Bibliography of Comparative Education, ed. Philip G. Altbach, Gail P. Kelly, y David H. Kelly (Nueva York: Praeger, 1981), pag. 12-15.

4 Rolland G. Paulston, "Social and Educational Change: Conceptual Frameworks", Comparative Education Review 21 (Junio/Octubre 1977): 370-95.
} 
competidoras e identifica sólo dos paradigmas -las perspectivas de equilibrio y de conflicto- como bases para modelos conceptuales más específicos. Creo, sin embargo, que si consideramos la ideología como el sistema de la conciencia política o como el conjunto de ideas alrededor de las cuales un grupo de gente se organiza para acción política ${ }^{5}$, la noción de lograr la síntesis apartándose selectivamente de diferentes paradigmas que tengan raíces ideológicas competitivas, es incierta. Además, Paulston falló al no identificar una tercera perspectiva teórica principal, —el enfoque del "problema"- que difiere sustancialmente de los paradigmas de equilibrio y conflicto.

Para mostrar qué tan irreconciliables son estos paradigmas, imbuidos como están de ideologías rivales, examinaré dos debates. El primero fue entre Philip Foster por una parte y Martin Carnoy y otros por la otra - El segundo fue entre Margaret Archer y Admund King. Estos debates representan a mi juicio los intercambios más acerbos, pero quizá los más significativos que hayan favorecido la literatura sobre la educación comparada. A riesgo de simplificar demasiado, rotularé los sistemas que compiten en estos debates como "neo-positivista", "neo-Marxista" y "neo-relativista" Los neopositivistas tienden a conectar el análisis deductivo —nomológico, pretendiendo hacer generalizaciones de tipo legal utilizando múltiples datos de naciones o sociedades, para una explicación funcional, en contraste con los positivistas "ortodoxos" que se preocupan solamente por establecer leyes universales. Esto no quiere decir que en todos los casos los positivistas utilizan datos multinacionales o multiculturales; se pueden centrar en una sociedad en particular utilizando un sistema que requiere réplica en otras sociedades. Los neo-marxistas consideran la ideología como omnipresente en todos los sistemas teóricos, a diferencias de los marxistas "ortodoxos" que sólo consideran que las teorías ideológicamente imbuidas son aquellas que apoyan el capitalismo y en contraste con los relativistas "ortodoxos", que se centran en la "verosimilitud" (en vez de la verdad) científica, los neorelativistas también se preocupan por la aplicación práctica de "racionalismo crítico" en situaciones particulares. Las refinadas distinciones entre los ortodoxos y las neo orientaciones son importantes para mostrar las procedencias de las teorías contemporáneas; mi interés sin embargo, está en los contrastes generales entre los sistemas del positivismo, el marxismo y el relativismo. Estos contrastes deben quedar claros en mi discusión de los debates.

Sin embargo, es importante reconocer primero que todo que la educación comparada incita a la ideología puesto que ese campo tiene utilidad práctica en la reforma de la escolaridad. Si la educación comparada no fuere más que un ejercicio académico, no daría motivo para el desarrollo de conciencia política. Empero, manifestamos casi una obsesión por la necesidad de lograr algún beneficio práctico del estudio comparativo. Pocas veces hemos considerado que el conocimiento es un beneficio primario por sí mismo o que la búsqueda del conocimiento fortalece la mente o nos dá una victoria personal sobre el ambiente. Tales beneficios aparentemente son muy fugaces y muy impermeables como demostración empírica para que justifiquen que les dediquemos nuestro tiempo y más aún los recursos de nuestras instituciones de investigación. La preocupación sobre la política adecuada y la infusión de ideología que informa la investigación de política debe quedar evidente en mí revisión de los debates.

\footnotetext{
${ }^{5}$ Ver H. Mark Roelof, Ideølogy and Myth in American Politics: A Critique of a National Political Mind (Boston: Little, Brown, 1976), pag. 4. Yo prefiero la definición de Roelof a la de otros que hacen poca distinción entre ideología y epistemología o expresión cultural, porque mi propósito es el de mostrar que existe una parcialización intrínseca en los enfoques comparativos prevalecientes. Por ejemplo, la definición de Wuthnow de que "cualquier subconjunto de interpretaciones simbólicas, que de hecho sirva como vehículo para la expresión y transmisión de significados colectivamente compartidos" — no es apta para mi propósito. (Ver Robert Wuthnow, “Cornparative Ideology”, International Journol of Comparativa Sociology 22 (1981): 121-40, a 121).
} 


\section{El debate Foster-Carnoy y otros}

Este intercambio se centró en la política educacional para los países en vía de desarrollo. El principal argumento de Foster fue que en estos países "ningún tipo de planeación educativa tendrá éxito a menos de que se base en las aspiraciones y expectativas de la mayoría de la población o de que proporcione estructuras de incentivos que permitan que estas aspiraciones se modifiquen de acuerdo con metas racionales" Además, aún cuando "las exigencias a la constitución política central por igualdad, bienestar y desarrollo excedan ampliamente la capacidad del sistema para responder, la respuesta a este problema es menos y no más concentración de autoridad"6.

Es difícil encontrar una manifestación más consagrada a la acción democrática en la educación que la de Foster. Pero esta afirmación aparentemente democrática está modelada por un pensamiento funcional y una metodología positivista, que no son ideológicamente neutrales. Aun cuando la literatura neo-marxista sobre las incapacidades de funcionalismo es de todos conocida, vale la pena examinar la crítica de Carnoy de Devon al punto de vista de Foster.

Carnoy comienza su análisis mostrando que la posición de Foster es schumptereriana; es decir, que considera el sistema del mercado como comparativamente justo e imparcial y como ampliamente conducente al desarrollo económico. La interferencia del estado en las actuaciones del mercado merma la equidad inherente y la eficiencia de ese sistema y por consiguiente generalmente es injustificable. Carnoy sostiene sin embargo, que el modelo de Schumpeter es ingenuo, que el estado en los países no socialistas en vía de desarrollo no está controlado por partes desinteresadas sino por la burguesía local y por grupos extranjeros ex-coloniales que buscan más bien estabilidad económica en sus propios intereses que una reforma auténtica y que la toma de decisiones democráticas y descentralizadas.

De acuerdo con Carnoy, el "estado de ánimo" colonial que Foster le atribuye a la interferencia continuada con fuerzas "naturales" del mercado no es una característica efímera de los estados en vía de desarrollo sino el producto de un sistema económico firmemente arraigado y de una estructura social "esencial al funcionamiento del capitalismo dependiente y de la élite relativamente pequeña que se beneficia de ella". El estado para Carnoy no es un manipulador frívolo del mercado sino un mecanismo principal a través del cual sistemáticamente se controlan las masas durante el proceso de desarrollo. Las escuelas sirven como una parte importante del aparato represivo del estado socializando y preparando cognocitivamente mano de obra para la producción capitalista de bienes. La idea de que el estado puede simplemente abstenerse de interferir con el mercado es fatua, sino maliciosa, porque ignora los intereses creados de las élites quienes los manipulan haciendo aparecer que el estado puede ser un actor justo y políticamente neutral ${ }^{7}$. Devon además ataca a Foster por su autoproclamada neutralidad como científico social. “¿Cómo puede esta extensa defensa de la economía Laissez-faire con un sistema político descentralizado ser considerada como políticamente neutral? En algún momento Foster explícitamente advierte que "el estado no debe actuar" con respecto a un asunto particular de política, y en ninguna parte está claro que él ofrezca alguna alternativa. En efecto, hasta un grado curioso, Foster reduce la educación a la

\footnotetext{
${ }^{6}$ Philip Foster, "Dilemmas of Educatiorial Deveiopment: What We Might Learn From the Past", Comparative Educatlon Review 19 (Octubre 1975): 375-92, cita en 393.

${ }^{7}$ Martin Carnoy, "The Role of Education in a Strategy for Social Change", Comparatlve Educatión Review 19 (Octubre 1975): $393-$ 402 .
} 
economía y la economía a la política, puesto que al haberse negado a discutir las importantes funciones políticas y sociales de la educación, su ex posición contextual de la economía primordialmente la hace en términos de prescripciones políticas ${ }^{8}$ “.

La respuesta de Foster a sus críticos es positivismo clásico y se puede resumir en la siguiente observación suya: "Se ha sugerido que yo me refugié en los datos; tomo esto como un cumplido y encuentro que esta es una alternativa ampliamente preferible a refugiarme en la retórica"9. Para Foster, los análisis neo-marxistas de las estructuras educacionales son excursiones elaboradas y tergiversadas de una realidad que sólo existe en la mente de los neo-marxistas. Sus críticas no se basan en métodos cuidadosos para probar las suposiciones sino en ideas predigeridas del "orden mundial". Para ellos el futuro es conocido, y la transformación revolucionaria es inevitable. Tal criterio da lugar a un sentido de dimensión de las capacidades de la educación para influir el orden social, y por consiguiente "los intentos para la dirección social están condenados al fracaso y no pasan de ser intentos por reparar un sistema social ya "sentenciado" 10 .

Por eso Foster reprende a los neo-marxistas por su desdén de validación empírica para entender la realidad. Devon afirma que la pretensión de Foster de la objetividad empírica es hipócrita en vista de su inclinación a prescribir la política, y Carnoy protesta ante el funcionalismo de Foster, que evalúa un sistema en términos de su capacidad para satisfacer las exigencias necesarias para sobrevivir a la luz de fuerzas que amenazan un cambio. Vale la pena anotar que cada lado acusa al otro de promover pasividad y de obstruir el desarrollo auténtico. Foster aduce que la realidad preinterpretada de los neomarxistas da lugar a un sentido de estar tratando con sistemas sociales ya sentenciados, y los neo-marxistas afirman que la idea de Foster de sistemas auto regulados e integrados funcionalmente se resiste al cambio. Además, las diferencias reales entre las orientaciones neo-marxistas y neopositivistas en la educación comparada no han sido tanto en términos de la mayor propensión de la última para utilizar datos empíricos sino de la tendencia de estos grupos para aplicar el conocimiento -inclusive datos idénticos - para fines diferentes. Para los positivistas, los marxistas utilizan la información para corroborar sus concepciones predeterminadas del cambio social. Para los Marxistas, la fachada positivista de la objetividad en la recopilación de datos empíricos empaña su apoyo a la estructura socio-económica prevaleciente.

Es interesante que dos posiciones tan ampliamente contrarias puedan conjuntamente dominar tantas ideas en la educación comparada. También vale la pena anotar el poco esfuerzo que se ha hecho para examinar los puntos de partida divergentes sobre los cuales yacen estas dos posiciones y gran parte de nuestra literatura. Deseo por lo menos comenzar este examen, primero con un breve repaso de las suposiciones metodológicas de Anderson y Foster, quienes en fragmentos separados establecieron el neo-positivismo a comienzos de la década del 60 como el paradigma de la corriente principal para la educación comparada.

\footnotetext{
${ }^{8}$ Richard F. Devon, "Foster's Paradigm-Subrogate and the Weaith of Underdeveloped Nations", Comparative Education Review 19 (Octubre 1975): 403-13, cita en 406.

${ }^{9}$ Philip Foster, “Commentary on the Commentaries", Comparatlve Education Review 14 (Octubre 1975): 423-33, cita en 424. Que los argumentos de los eruditos radicales no son más que retórica vacía es un tema al que Foster ha regresado recurrentemente. En su alocución presidencial de 1971 Foster adujo que los radicales están "atrapados en un nivel de retórica que les dificulta captar las implicaciones totales de sus argumentos" (Philip Foster, "Presidential Address: The Revolt against the Schools", Comparative Education Review 15 (Octubre 1971): 268).

${ }^{10}$ Foster, "Commentary of the Commentaries", pág. 423.
} 


\section{Positivismo en la Educación Comparada}

Anderson aduce que el propósito de la educación comparada es el de "abordar sistemas complejos de correlaciones entre características educativas y entre éstas y los rasgos de la estructura social, con poca referencia a la individualidad de la sociedad de la que se obtuvieron nuestros datos. Por convencionalismo..., el estudio comparativo comprende la correlación a través de las fronteras de las sociedades —bien sea que estas sociedades representen diferentes siglos en un área o sociedades y subsociedades espacialmente diferentes" ${ }^{11}$. Con especial cuidado de categorizar las observaciones empíricas, correlacionando las variables precisamente delineadas y probando sistemáticamente proposiciones obtenidas a través de la experiencia, Anderson cree que el método comparativo puede revelar patrones ordenados y repetitivos de cambio social. Tanto él como Foster igualan la comparación con la descripción de covariación de Nadel que considera que las situaciones sociales consisten no de detalles al azar sino de hechos que tienen cohesión por algún "nexo significativo o idoneidad intrínseca"12 Las escuelas funcionan en forma sólo parcialmente autónoma dentro de un patrón que contiene otras instituciones sociales; el método comparativo considera a la educación como una variable específica e intenta controlar su asociación con otras variables sociales para determinar relaciones invariantes. En esta forma la comparación se utiliza para "esclarecer procesos abstraídos del tiempo y aún parte de las concepciones de etapas (evolucionarias)"13. Anderson y Foster ponen de manifiesto su afinidad con el positivismo evadiendo investigación de la singularidad y orígenes esenciales de los fenómenos sociales discretos - tan característicos del historicismo extremo- con el objeto de dar claridad a las proposiciones acerca de educación y sociedad ${ }^{14}$.

Anderson identifica tres tipos de correlaciones necesarias para el desarrollo del campo. Estos son (1) patrones de relaciones entre varios aspectos de sistemas educativos; (2) una tipología de sistemas docentes que condense muchos patrones de datos en estructuras simplificadas, permitiendo así un mayor nivel de abstracción; y (3) relaciones entre varias características educativas y distintivos sociológicos, económicos y no educacionales asociados. Sin embargo, es interesante observar que en los 20 años en que se ha establecido la posición positivista en la educación comparada, los humanistas que trabajan en esta tradición han hecho sólo progresos marginales en la identificación de patrones adecuados de relaciones y en el establecimiento de una tipología de sistemas educativos, aun cuando los estudios de Hopper, Archer y Anderson, pueden constituir excepciones $^{15}$. En los ensayos sobre educación ${ }^{16}$ casi no se encuentran estudios holísticos, que midan las variables teóricas en grandes muestras mundiales de culturas

\footnotetext{
${ }^{11}$ C. Arnold Anderson, "Methodology of Comparative Education", International Review of Education 7 (1961): 24-43, cita en 29.

12 Ibid., y PhiUp Foster, "Comparative Methodology and the Study of African Education",Comparative Education Review, vol. 4 (Octubre 1960), Ver también S.F, Nadel, Foundations of Social Anthropology (Glenco, III.: Free Press, 1951), pag. 224.

${ }_{13}$ Anderson, "Methodology of Comparative Education", pag. 28.

${ }^{14}$ El positivismo moderno alcanzó su zenit bajo la guía de Rudolf Carnap en la década del 30 en la Universidad de Chicago, donde Anderson y Foster escribieron sus trabajos sobre metodología comparada (ver Rudolf Carnap, "Testability and Meaning", Philosophy of Science, Vols. 3.4 (1936-37).

${ }^{15}$ Earl I. Hopper, "A Typology for the Classificatlon of Educational Systems", Soclology 2 (1968): 29-46; Margaret Archer, Social Origins of Educational Systems (Beverly Hills, Calif.: C. Arnold Anderson, "Social Selection in Educatlon and Economic Development”. mimeógrafo (Departamento de Educación del Banco Mundial, Febrero de 1982).

${ }^{16}$ Anderson específicamente menciona el estudio de parentesco de Murdoch y el estudio de organización económica de Udy que muestran métodos holísticos como modelos para análisis, comparativo (Anderson, "Methodology of Comparative Education", pág, 30). Ver G.P. Murdock, Social Structure (New York: Macmillan, 1949); y Stanley Udy, Organization of work (New Haven, Conn.: HRAF Presa, 1959). Qulzá los únicos ejemplos de investigación holística que se encuentran en la literatura sobre educación son Erwin H. Epstein, "Croas-cultural Sampling and a Conceptualization of 'Professional' Instruction", Journal of Experimental Education 33 (verano 1965): 395-401; y John D. Herzog, "Deliberate Instruction and Household Structure: A Cross-cultural Study", Harvard Educational Review 32 (1962): 310-42. Para una descripción de los primeros desarrollos del enfoque holístico, ver John W.M. Whiting, "The Cross-Cultural Method", in Handbook of Social Psychology, ed. Gardner Lindsey, 2 vols, (Cambridge, Mass.: Addison-Wesley, 1954), 1; 523 -31.
} 
humanas y prueben las relaciones entre ellas, como los propuestos por Anderson, y han surgido retos al positivismo que son lo suficientemente serios para amenazar el lugar que éstos ocupan en el campo.

Se han presentado obstáculos notables para el avance de una tradición positivista en la educación comparada. El primero es el escepticismo tácito pero penetrante sobre lo que Kaplan denomina como el "mito de la metodología" —la idea de que no importa lo que hagamos con tal que lo hagamos bien- que tiende a estar asociada con el positivismo"17. La auto-convicción de la metodología puede ser un síntoma de madurez de un campo, pero si es excesiva puede tener un efecto represivo sobre el adelanto de investigación. Los practicantes con frecuencia se han mostrado renuentes a abandonar los enfoques descriptivos y aun impresionistas que son convenientes de aplicar a problemas prácticos en beneficio de la pureza metodológica.

El segundo obstáculo es la tendencia a basarse indiscriminadamente en naciones y no en entidades más discretas tales como grupos étnicos o tribales como unidades de análisis, La comparabilidad analítica de las naciones es ampliamente problemática, como lo es la posibilidad de muestras confiables cuando el número de unidades disponible para comparación es tan pequeño. Sin embargo, Noah y Eckstein en el más extenso trabajo que haya adelantado la orientación positivista desde los fragmentos iniciales de Anderson y de Foster $^{18}$, ni siquiera consideran la investigación holística por mucho que ese enfoque pueda ser la extensión más lógica del positivismo. En efecto, no es sorprendente que Noah, en su alocución presidencial de 1974 (unos pocos años después de la aparición del libro que publicó con Eckstein, Toward a Science of Comparative Education) admitió las limitaciones de los estudios entre naciones, Lo que sí es sorprendente es su progreso en los estudios micro y en el enfoque de los "casos que puedan estar muy por fuera del plano de regresión" para llenar brechas de comprensión creadas por las pequeñas variantes a nivel de un país o de varios países que los investigadores estaban tratando de explicar como logros ${ }^{19}$. En vez de sugerir la importancia de refinar las unidades de análisis para progresar en la "ciencia" de la educación comparada. Noah se aproximó a la idea de que la base científica del campo — la búsqueda sistemática de generalizaciones y patrones repetitivos en los fenómenos sociales había llegado casi al máximo de su progreso.

El tercer obstáculo es el más importante y en el que deseo centrar la atención, Me refiero al componente ideológico en la orientación positivista. Irónicamente, el positivismo - o el empirismo científico como a veces se le denomina- surgió como una reacción contra la explicación religiosa, metafísica y política.

No obstante, encontramos que el impulso positivista se ve cada vez más atacado debido a su inclinación ideológica. El positivismo clásico está abierto a la crítica porque el grado de claridad que puede brindar a las proposiciones es necesariamente limitado; los criterios para la confirmación o invalidación de las proposiciones deben ser lo suficientemente liberales como para permitir afirmaciones que contengan términos

\footnotetext{
${ }^{17}$ Abraham Kaplan, "Poaitivism", en International Encyclopedia of the Social Sciences, ni. David L. Silla (New York: Macmillan, 1968), 12;394.

${ }^{18}$ Noah y Eckstein (n, I, Above).

${ }^{19}$ Harold J. Noah, "Fast-Fish sud Loose-Fish iii Comparative Education", Comparative Education Review 18 (Octubre 1974): $341-$ 47. Al discutir las limitaciones de los macro estudios, Noah se refirió ampliamente a la investigación sobre logros internacionales en matemáticas (ver Torsten Husen, ed,. International Study of Achievement in Mathematics: A Comparison between Twelve Counfries (New York: Wiley, 1967), vols, 1.2). 
teóricos, cuya confirmación debe permanecer remota e indirecta, y por lo tanto susceptible a ideologías, mitos, e inclusive a la metafísica. Sobre este punto Max Weber ha dado testimonio elocuente, y no me resta sino referirlos a su trabajo ${ }^{20}$. Pero la mayoría de quienes han estado a favor de una medición más precisa de las variables y de una mayor claridad en las proposiciones sobre la educación han sobrepasado deliberadamente la búsqueda de regularidades de tipo legal. Por ejemplo, Anderson afirmó hace dos décadas que el gran "eslabón perdido" en la educación comparada es la "ausencia casi total de información sobre los resultados o productos de los sistemas educativos ${ }^{21}$. Al contrario de los positivistas clásicos que se contentaban con encontrar conexiones "lógicas" entre las declaraciones que podían ser verificadas, y que finalmente conducían a una síntesis amplia de dicho conocimiento, Anderson y la mayoría de los demás neo positivistas en educación comparada se preocupan por las conexiones causales, No se preocupan solamente por la covariación entre la educación y otras variables, sino también por las consecuencias de la educación como una variable independiente, especialmente por cuanto ha afectado el desarrollo o "modernización,' de las naciones. Es a este respecto que han quedado expuestos a la más seria de todas las críticas -aquella de la inclinación ideológica.

El "desarrollo" no es un concepto sin valor. Está imbuido de significado normativo, y, de hecho, su contenido ha cambiado al igual que los estados finales con los que se le ha asociado. Por ejemplo, Packenham ha sostenido que al igual que se revisaron los valores políticos prevalecientes en los Estados Unidos durante el período posterior a la segunda Guerra Mundial, se revisé también el concepto de desarrollo. Originalmente el desarrollo se consideraba en términos de crecimiento económico y fue transformado en una política por el Plan Marshall y la Legislación Punto Cuatro. Poco tiempo después, como se refleja en la Ley de Seguridad Mutua, el desarrollo se llegó a asociar, en parte, con la seguridad militar. Aún después, las metas de participación política y el establecimiento de instituciones democráticas, comprendidas, por ejemplo, en el Título IX de la Ley de Asistencia Extranjera de 1966, igualaron al crecimiento económico en la definición del desarrollo ${ }^{22}$. Más recientemente, la reducción de la desigualdad se ha unido al conjunto de componentes de las proposiciones que conforman el "desarrollo" 23 . Para resumir, los significados que se le han asignado al desarrollo han sido determinados por la gama de valores que se utilizan para definir los estados finales.

No obstante la aceptación incuestionable del desarrollo como una meta universalmente deseable, por parte de los comparativistas en la tradición neopositivista, el desarrollo nunca podrá estar totalmente basado en premisas objetivas, racionalistas e incontestables. De hecho, los eruditos han venido observando la aparición del "sobredesarrollo" en algunas sociedades: o sea, un estado donde los componentes intangibles de la existencia humana decaen, a medida que los índices tangibles de desarrollo mejoran ${ }^{24}$. Los beneficios del desarrollo, incluyendo los resultados y productos

\footnotetext{
${ }^{20}$ Max Weber, Methodology of the Social Sciences, trad. y ed. por Edward A. Shils y Henry A. Finch (Glencoe, III.: Free Press, 1949), paga. 49-112. Véase también Kaplan, pgg. 390.

${ }^{21}$ Anderson, "Methodology of Comparatiye Education", pag. 30;

${ }^{22}$ R.A, Packenham, Liberal America and The Third World (Princeton University Presa, 1973).

${ }^{23}$ Véase, v.g., Irma Adelman y C.T. Morris, Economic Growth and Social Equity in Developing Countries (Stanford, Calif.: imprenta de la Universidad de Stanford, 1973); y Dudley Seers, "The Meaning of Development", en The Political Economy of Development and Underdevelopment, ed. O.K. Wilber (Nueva York: Random House, 1973).

${ }^{24}$ Robert N. Beflah, Beyond Belief (Nueva York: Harper \& Row, 1970); Dean C. Tibbs, "Modernization Theory sud the Study of National Societles: A Criticai Perspective,. Comparative Studies in Society and History 15 (1973): 199-226; 5. Chodak, Societal Development (Nueva York: Imprenta de la Universidad de Oxford, 1973); C.H, Anderson, The Sociology of Survival (Homewood, 
de la educación, deben permanecer abiertos a discusión si las patologías sociales son un subproducto de una mayor riqueza material e igualdad política. A los neo-marxistas se les puede acusar de una relativa falta de atención a la validación empírica, pero ellos tienen mucha razón al atribuir la inclinación ideológica al trabajo de neopositivistas como Foster y Anderson. Todos los eruditos, como miembros de la sociedad, son parte de la realidad estudiada, y sus creencias, anteriores a su escolaridad, están influidas por la realidad histórica de la que participan ${ }^{25}$. Por mucho que los positivistas puedan admitir la probidad de la disociación personal en el diagnóstico de un asunto, el proceso de la investigación misma transforma la realidad social. Se debe tener en cuenta que una generalización respecto a la realidad social es una declaración sobre comportamiento "típico" o "regular"; un mecanismo de comportamiento científicamente descrito no es simplemente un hecho empírico que describe una muestra de observaciones, sino un modelo de avenencia para todo el universo de individuos a quienes se aplica la declaración. El comportamiento típico es comportamiento normativo. Cuando se difunde aquello que es típico, con frecuencia se le hace más típico. Demostrar que los estudiantes de ingeniería obtienen empleos mejor remunerados no es simplemente un hallazgo neutral; puede tener el efecto de producir más ingenieros. Merton reconoció esto cuando escribió sobre las profecías "que por su propia naturaleza tienden a cumplirse" — pronósticos que influyen su propia realización ${ }^{26}$.

\section{El debate Archer-King}

Quiero mencionar ahora el segundo debate fundamental sobre educación comparada -aquel entre Archer y King - donde el positivismo se ve retado, por otra parte, por exponentes del enfoque del problema, a quienes yo llamo neo-relativistas, Por muy radicales que puedan ser los neo-marxistas en comparación con los neo-positivistas, los neo-relativistas son conservadores.

El debate entre Archer y King se precipitó cuando King, criticó el libro reciente de Archer, titulado "Social Origins of Educational Systems" en un comentario publicado en "Comparative Education" revista de la cual King es editor ${ }^{27}$. En pocas palabras, King considera el trabajo de Archer como "una cuasi-teología sobre el "pensamiento y la teorización sobre sistemas educativos', 'características universales de elaboración estructural', y así sucesivamente — todas ligadas a través de la 'identificación' repetitiva de fenómenos, secuencias, 'causación', 'determinantes', 'leyes', 'generalizaciones empíricas importantes, leyes de composición, que entonces le permitirían a uno computar situaciones complejas', leyes macrosociológicas y el resto del aparato tan desacreditado que trata de forzar los sistemas educativos y otros sistemas hacia las tipologías dilectas de algunas aulas de seminarios" ${ }^{28}$. De hecho, el libro de Archer es un ejemplo de positivismo ortodoxo, y debe quedar claro de mis observaciones anteriores que la caracterización de King del volumen de 'una cuasi-teología' no es simplemente una crítica del libro sino de la orientación que representa.

"Social Origins" es una obra muy sutil y compleja y representa el intento más ambicioso que se haya hecho por lograr el tipo de síntesis amplia de las proposiciones sobre educación que ansían los positivistas. Se trata de los mecanismos a través de los cuales

\footnotetext{
III.: Dorsey, 1976); y Daniel Chirot, "Changing Fashions ni the Study of tbe Social Causes of Econonuc and Political Change", en The State of Sociology: Problema and Prospects, ecl. James F. Short, Jr. (Beverly Hills, Calif.: Sage, 1981), pags, 259-82.

${ }^{25}$ Véase Jerzy J. Wiatr, "Sociology-Marxism-Reality", en Marxum arid Sociology: Views from Eastern Europe, ed. Peter L. Berger (Nueva York: Appleton-Century-Crofts, 1969), págs. 18.36.

${ }^{26}$ Robert K. Merton, Social Theory ami Social Structure (Nueva York: Free Press, 1957).

${ }^{27}$ Archer, Social Origins of Educational Systems; La reseña de King está en Comparative Education 15 (Octubre 1979): $350-52$.

${ }^{28}$ Edmund King. "Prescription or Partnership ni Comparative Studies of Education?" Comparative Education 16 (Junio 1980): 18595, cita en la 186.
} 
se transforman en política las presiones para el cambio o estabilidad educacional. Pero lo que vale la pena anotar aquí es que la síntesis no se obtiene con el uso de muestras macro en muchas sociedades. Por el contrario, Archer hace énfasis en la determinación histórica y limita su análisis a la política educativa de solamente cuatro países: Dinamarca, Inglaterra, Francia y Rusia. Al examinar los contextos dentro de los que se presenta el cambio, Archer revela las fuerzas estructurales que alientan la supervivencia de tipos distintivos de sistemas educativos y la naturaleza de su adaptación a ambientes en transformación. En otras palabras, lo que Archer no logra en términos de confiabilidad en muestras representativas, lo trata de compensar haciendo un análisis exhaustivo de los factores y fuerzas dentro de sociedades particulares. A pesar de su cuidadosa atención a la determinación contextual, ella evita el tipo de historicismo extremo que Anderson objeta. Ella permanece fiel a la tradición positivista observando las regularidades y extrayendo generalizaciones demasiado amplias — aunque en extremo cuidadosas - de los datos sobre centralización y control de la educación, grupos de interés, élites políticas y recursos económicos, Como reacción a su libro, Craig comenta que "uno se ve tentado a concluir que ya se conoce todo lo que quisiera saber sobre los orígenes y desarrollo de los sistemas educativos," 29 .

La crítica de King a "Social Origins" nos muestra un concepto sobre la tercera orientación teórica más importante del campo y su impulso ideológico correspondiente, Los neo-relativistas - proponentes del enfoque del problema"- y los neo-marxistas pueden tener puntos de vista mutuamente incongruentes, pero comparten su escepticismo sobre el pensamiento y métodos positivistas. King opina simplemente que las proposiciones nacionalmente generalizadas no son válidas, que todas las afirmaciones teóricas relacionadas con la educación se deben hacer en su totalidad dentro de contextos particulares, y que el propósito principal de la comparación no es la explicación sino el perfeccionamiento de la educación, es decir, dentro del contexto de situaciones específicas. Por muy atenta que esté Archer al detalle contextual, no es lo suficiente para satisfacer a King, en vista de su tendencia a utilizar estereotipos tales como "la constitución política impenetrable" y "el sistema centralizado", como "ideas en las que se pueden sintetizar los fenómenos de la vida real, no solamente de un país a otro y de un contexto a otro, sino de una era a otra, y de una etapa de desarrollo a circunstancias totalmente diferentes" 30 , Para King, el "mensaje" macrosociológico de Archer no es más que "un sucesor de nuestros días de la ortodoxia teológica"

La reacción de Archer a la crítica de King reviste igual interés, no solamente por lo que muestra sobre su punto de vista acerca del relativismo, sino por lo que refleja sobre su orientación positivista. En su rechazo al valor prescriptivo de la comparación se muestra como una positivista más ortodoxa que Anderson o Foster, quienes se preocupan tanto por las implicaciones de la política educacional en el desarrollo, como por la explicación y generalización. Las observaciones de Archer son esclarecedoras:

¿Por qué entonces encuentra King tan deseable el método comparativo? la respuesta se encuentra arraigada en el núcleo del propósito "reformativo de la educación comparada, Se debe a que el método comparativo nunca nos podrá decir lo que se debería hacer. Para King, la prueba final de un marco teórico es simplemente constatar si "puede ayudar al desarrollo de la política". De ahí que su confusión entre la validez y la

\footnotetext{
${ }^{29}$ John E, Craig, “On the Development of Educational Systems”, American Journal of Education 89 (Febrero 1981): 189-211, cita en la 201.

${ }^{30}$ King, pág, 187.

${ }^{31}$ Ibid., p fg, 195.
} 
utilidad corra paralela a la anterior elisión entre hechos y valores, y entre explicación y prescripción... El criterio instrumental de la validez tiene todos los defectos... porque el instrumentalismo en general, señaladamente no tiene nada que ver con la verosimilitud, y se podría decir que mucho menos en el campo de los programas políticos. Además, la formación de la política es, en su forma más depurada, un proceso político, dentro del cual el Educador Comparativo es movido de un lado a otro, más como un peón que como un Rey. Cualquiera de estos educadores harían mucho mejor en recluirse en sus seminarios para tratar de entender este proceso con la ayuda del método comparativo, que en unirse ingenuamente a uno de los "talleres" de comparación que moldean la política",.. que según King han "contribuido mucho a reforzar la Educación Comparada desde finales de la década del $50 . . .32$.

\section{La inclinación ideológica del Neo-positivismo}

Ya debe estar claro el concepto de las suposiciones teóricas de la orientación positivista en la educación comparada, al igual que las objeciones al positivismo de los neo-marxistas y los neo-relativistas. Los positivistas creen que los patrones ordenados y repetitivos de los procesos sociales relacionados con la educación se pueden abstraer del tiempo y del espacio ensayando sistemáticamente proposiciones extraídas de la experiencia. Y la mayoría de los positivistas, y me refiero aquí a los neo-positivistas, han tratado de aplicar métodos empíricos sistemáticos a las observaciones acerca del papel de la educación en el desarrollo nacional. Es en este respecto donde los neo-marxistas y los neo-relativistas han sido más convincentes. Al mostrar que el "desarrollo" no es un objetivo sin valores y universal-mente aceptado, han demostrado la inclinación ideológica de los neo-positivistas. Yo sostengo, sin embargo, que los neo-marxistas y los neo-relativistas son culpables de prejuicio: sus suposiciones también están informadas por la ideología.

\section{La inclinación ideológica del neo-marxismo}

Los marxistas y los relativistas niegan la validez de abstraer la naturaleza del hombre independientemente de las condiciones socio-históricas particulares. En especial los marxistas creen que el carácter del individuo es siempre dinámico y que la existencia humana es un proceso de llegar a ser. Para Marx, "la verdad nunca puede estar por encima de la estructura económica de la sociedad y del desarrollo cultural determinado por la misma"33.

Para él, la ideología se aplica a teorías que universalizan momentos históricos proyectando sus características más allá del momento histórico como rasgos inmutables de la naturaleza humana. Los marxistas ortodoxos comparan la ideología con los escritos de intelectuales que, aduciendo una validez universal y objetiva de las proposiciones sobre la realidad social, que debe atribuir permanencia y estabilidad a las relaciones sociales, ayudan a preservar el orden capitalista ${ }^{34}$. Invariablemente la ideología da lugar a una falsa conciencia, característica exclusiva de intelectuales y capitalistas.

\footnotetext{
${ }^{32}$ Margaret Archer, "Sociology and Comparative Education: A Reply to Edmund King", Comporative Education 16 (Junio 1980): 179-85, cita en la 184.

${ }^{33}$ Karl Marx, A Critique of the Gotha Program (Nueva York: International Publishers, 1938), y The Poverty of Philosophy (Moscú: casa Editora en Idiomas Extranjeros, m.d.).

${ }^{34}$ Ver Koula Mellos, “The Concept of Ideology in Marx”, Social Praxis 7 (1980); 5-19.

Digitalizado por RED ACADEMICA
} 
Sin embargo los neo-marxistas, y particularmente Gramsci, hacen una distinción entre la falsa conciencia y la ideología. Para ellos, la falsa conciencia —olvidando las relaciones sociales de producción que prevalecen en la sociedad- no está limitada a los intelectuales y capitalistas; la clase obrera en las sociedades capitalistas, también es presa de la falsa conciencia. Sin embargo, la falsa conciencia de la clase obrera no es ilusoria en el mismo sentido que la de la burguesía; la decepción de la primera no es total, porque estar oprimido significa sentir opresión y tener que aprender a manejarla. La falsa conciencia se convierte en la forma normal de percibir y actuar dentro de la sociedad capitalista, pero las tendencias inherentes al proceso económico básico de la acumulación capitalista impiden que dicha falsa conciencia sea permanente y arraigada entre los trabajadores. Al contrario de Marx, los neo-marxistas ceden a un impulso ideológico; para ellos, el desarrollo de la conciencia de la clase revolucionaria es un proceso ideológico de moldear los conceptos fragmentarios de los trabajadores. Por lo tanto, la ideología marxista se ofrece para contrarrestar la ideología burguesa ${ }^{35}$.

El papel de la educación en el neo-marxismo es de obvia importancia. La Escuela es una espada de doble filo; representa las condiciones de represión social de la sociedad capitalista, pero es también en potencia el instrumento para la disipación de la falsa conciencia. La educación en las democracias capitalistas liberales promueve brechas en las clases sociales al transmitir a cada generación sucesiva una tergiversación estructurada de la realidad. En vez de buscar la "verdad", las escuelas capitalistas imponen una ideología que engaña al proletariado para que contribuya con su trabajo al proceso de producción, beneficiando solamente a las clases dirigentes. Esto lo logran enseñando la idea de un mundo positivista que hace énfasis en el descubrimiento a través de la experiencia y de las impresiones sensoriales. Sin embargo, como Freud lo ha demostrado, las impresiones a través de los sentidos son engañosas; las personas tienden a seleccionar "hechos" particulares de entre una multitud infinita de posibilidades, para después ordenar y catalogar sus observaciones de acuerdo con la forma como éstas se acomoden dentro de su patrón particular. Todos somos presa de decepciones, mecanismos de defensa tergiversados, prejuicios, presiones de grupo, e ideas mentales que tuercen nuestras percepciones de la realidad. Sin embargo, los positivistas, que confían en la experiencia sensorial para obtener datos, y cuya idea de la realidad está por consiguiente moldeada por los sentidos falibles, son particularmente susceptibles a dichas distorsiones. En vez de confiar en los conocimientos objetivos, su confianza en las percepciones de los sentidos les origina una tergiversación de la realidad. En vez de promover al individuo como fuente de conocimiento, la ideología positivista, al considerar el conocimiento como algo que se debe experimentar, transforma al individuo en un simple agente de la producción del conocimiento. Por lo tanto, la educación en la sociedad capitalista se puede considerar en forma metafórica como una fábrica, cuyo producto es el conocimiento, pero que existe aparte y fuera del control del individuo que trabaja para producirlo $^{36}$. Analistas del sistema mundial, tales como Arnove, han llevado su crítica al

\footnotetext{
${ }^{35}$ Antonio Gramsci, Selections from the prison Notebooks (Londres: Lawrence \& Wishart, 1971). Véase también Georg Lukacs, History and Class Consciousness (Cambridge, Mass.: MIT press, 1972); J. Femia, "Hegemony and Consciousness in the Thought ofAntonio Gramsci”, Political Studies 23 (1975): 29-48; y Ron Eyerman, “ False Consciousness and Ideology in Marxist Theory”, Acta Sociológica 24 (1981): 43-56.

${ }^{36}$ Los escritos neo-marxistas relacionados con la educación han aumentado considerablemente en los últimos años. Para una descripción de sus corrientes más influyentes véase Vandra Lea Masemann, "Critical Perspectives on Issues in Comparative Education" (ponencia presentada en la reunión de la Sociedad de Educación Comparada e Internacional celebrada en Vancouver, Canadá, en Marzo de 1980); y Pierre Bourdieu y Jean-Claude Passeron. Reproduction in Education Society and Culture (Beverly Hills, Cailf.: Sage, 1977).
} 
plano internacional en un intento por mostrar que las escuelas contribuyen al surgimiento y consolidación de un sistema económico mundial paralizado por el capitalismo ${ }^{37}$.

Aun cuando los neo-marxistas no niegan que, al igual que los neo-positivistas, ellos también tienen una ideología, creen que su ideología marxista es superior. Harris ha llegado hasta proponer una prueba para juzgar la veracidad de la perspectiva marxista de la realidad, contra el punto de vista liberal democrático de los positivistas. El único criterio de la prueba es el grado en el que la ideología sirve por igual a todos los intereses sociales, económicos y políticos. No es de sorprender que Harris concluya que el positivismo, en un abierto contraste con el marxismo, no pasa la prueba por servir desproporcionadamente los intereses de la burguesía. Por ejemplo, la educación bajo el capitalismo enseña a los hijos de la clase obrera a aceptar el sitio que les ha sido asignado en la sociedad, mientras que legítima la posición elevada de los ricos. Esto lo hace en forma efectiva haciendo énfasis en el boato auto-profesado de la democracia liberal -la franqueza de la sociedad, el consentimiento político universal y las oportunidades para una movilización social ascendente a través del esfuerzo individualmientras que ignora los resultados: una movilidad social real relativamente pequeña y una constante inequidad en la distribución de la riqueza y los recursos. Así, los hijos de la clase obrera aprenden injustamente a culparse a sí mismos por su posición inferior, porque se ven imposibilitados para progresar socio-económicamente entre una supuesta multitud de oportunidades, y los hijos de la clase media o alta aprenden en forma similar a justificar su posición frente a aquellos que supuestamente no son lo suficientemente inteligentes o diligentes para ser mejores. De esta forma la escuela enseña una falsa conciencia a todo nivel social, manipulada por los ricos, puesto que ellos también creen en el mito de las oportunidades abiertas ${ }^{38}$.

Desafortunadamente los neo-marxistas son tan dados a exagerar sus derechos a defender su posición, como lo son los positivistas en defender la propia. Mientras que la negación de los positivistas de la inclinación ideológica no tiene fundamento, los neomarxistas están pisando terrenos igualmente inciertos al afirmar la superioridad de su ideología. Consideremos que para toda su falta de confianza en el empirismo, los neomarxistas dependen de la validez de ciertos derechos empíricos para la eficacia de su posición. Harris, por ejemplo, se basa en los hallazgos de Bowles y Gintis ${ }^{39}$ para mostrar que el éxito económico bajo el capitalismo es una función del sistema económico y tiende a sucederse en las familias casi independientemente de la inteligencia (medida por las pruebas de cociente intelectual (IQ)); que los ricos siguen siendo ricos y los pobres permanecen pobres independientemente de su capacidad intelectual. Los datos de I3owles y Gintis refutan los argumentos de geneticistas y sicólogos, principalmente de Jensen y Herrnstein ${ }^{40}$, de que la estratificación socio-económica se puede explicar mejor por el "hecho" de que la inteligencia, que se "reconoce" como altamente hereditaria, se va pasando dentro de los grupos económicos hasta tal punto que la educación simplemente no puede compensar las diferencias genéticas. Harris cree que tales argumentos, al centrarse más en el individuo que en las relaciones sociales como fuente de las diferencias económicas, están arraigados en una ideología al servicio de las clases y de los intereses creados; sus datos tienden a justificar la perpetuación de la desigualdad

\footnotetext{
${ }^{37}$ Robert F. Arnove, "Comparative Education and World-System Anaiysis", Comparative Education Review 24 (Febrero 1980): 4862; véase también Martin Carnoy, Education as Cultural Imperialism (Nueva York: McKay, 1974).

${ }^{38}$ Kevin Harris, Education and Knowledge: The Structured Misrepresentation of Reality (Londres: Routledge \& Kegan Paul, 1979).

${ }^{39}$ Samuel Bowles y Herbert Gintis, Schooling in Capitalist America: Educational Reform and the Contradictions of Economic Lifer (Nueva York: Basic, 1976).

${ }^{40}$ Arthur R. Jensen, "How Much Can We Boost IQ and Scholastic Achievement?" Harvard Educational Review 39 (1969): 1-123; Richard J. Herrnstein, "I.Q.” Atlantic Monthly 228 (Diciembre 1971): 43-58
} 
económica basada en las clases como originada por variaciones genéticas reales en los individuos. En contraste, los hallazgos de Bowles y Gintis, que supuestamente demuestran que la desigualdad económica está arraigada en la estructura misma de la sociedad y no puede ser explicada por la superioridad intelectual y genética de la clase dominante, están libres de distorsión ideológica.

Sin embargo, la posición de Harris es, cuando menos, dudosa. Tanto los hallazgos de Bowles-Gintis como los datos de Jensen-Herrnstein pretenden medir la influencia de la inteligencia genéticamente hereditaria sobre la productividad económica y el logro de un nivel específico. Queda por ver, sin embargo, que ellos han trabajado partiendo de diferentes conjuntos de datos que, aun cuando susceptibles a la evaluación empírica, no han sido aún sistemáticamente comparados, y que la "prueba" de Harris no puede producir resultados definitivos debido a las brechas existentes en el estado actual del conocimiento. Al igual que muchos otros ${ }^{41}$, Bowles y Gintis demuestran en forma persuasiva lo inadecuado de la posición de Jensen Herrnstein; pero aquí volvemos a encontrar que los datos de Bowles y Gintis, que pretenden demostrar que las escuelas sirven principalmente para desarrollar características no cognoscitivas necesarias para la reproducción de las relaciones de la producción en una economía capitalista, no han tenido mayor fundamento según afirman Olneck y Bilis ${ }^{42}$.

Además, la mayoría de la tesis de Harris se basa en el supuesto fracaso de los programas de educación compensatoria introducidos en los Estados Unidos en la década del 60 para igualar las oportunidades económicas entre los ricos y los pobres. Harris sugiere que estos programas no fueron más que simulaciones utilizadas para hacer que las personas creyeran en la retórica liberal democrática sobre el valor de las escuelas para promover la movilidad social. No obstante, estudios recientes indican no solamente que los programas de educación compensatoria pueden haber tenido un impacto mayor que las primeras investigaciones, como las que han reivindicado Coleman et al. y Jencks et al., sino también que las características de la escuela pueden afectar profundamente los resultados de los estudiantes, y que después de todo, las escuelas podrían romper los vínculos entre clase, raza y logro académico ${ }^{45}$ - Para nuestros propósitos, los hallazgos más importantes son los de Heyneman y Loxley, quienes, en un examen de diversas influencias sobre logro académico en Africa, Asia, América Latina y el Medio Oriente muestran que el poder del nivel socioeconómico para determinar el rendimiento es sustancialmente inferior en los países de más bajos ingresos, y que mientras más bajos sean los ingresos de un país, mayor será el poder de la escuela para determinar

\footnotetext{
${ }^{41}$ Véase L.J. Kamin, The Science and Politics of I.Q. (Nueva York: Wiley, 1974); N.J. Block y G. Dworkin, eds., The I.Q. Controversy (New York: Pantheon, 1976); Stephen Jay Gould, “Jensen's Last Stand”, New York Review of Books 27 (Mayo 1, 1980): 38-44; y Sandra Scarr, Race, Social Class and Individual Differences in I.Q. (Hillsdale, N.J.: Erlbaum, 1981). ${ }^{42}$ Michael R. Olneck y David B. Bills, "What Makes Sammy Rum? An Empirical Assessment of the Bowles-Gintis Correspondence
Theory", American Journal of Education 89 (Noviembre 1980): 27-61.
}

James Coleman, E. Campbell, C. Hobson, et al., Equality of Educational Opportunity (Washington, D.C.: Government Printing Office, 1966);Christopher Jencks, M. Smith, H. Arland, et al., Inequality: A Reassessment of the Effect of Family and Schooling in America (Nueva York;Basic, 1972).

Irving Lazar y Richard Darlington, Lasting Effects after Preschool (ERIC/ECE, 1979).

45 Diane Ravitch, The Revisionists Revised: A Critique of the Radical Attack on the Schools(Nueva York; Basic, 1978); Wilbur Brookover, Charles Beady, Patricia Flood, et al., School Social Systems and Student Achievement: Schools Social Systems and Student Achievement:Schools Can Make a Difference (Nueva York: Praeger, 1979); G. Madaus, T. Kellaghan, E. Rakow, y D. King, "The Sensitivity of Measures of School Effectiveness", Harvard Educational Review 49 (1979); 207-30; y M. Rutter, B. Maughan, P. Mortimore, y J. Ouston, con A. Smith, Fifteen Thousand Hours (Cambridge, Mass.: Imprenta de la Universidad de Harvard,1979). 
directamente el rendimiento de los estudiantes ${ }^{43}$. Estos hallazgos constituyen un reto a lo que sostienen los analistas marxistas del sistema mundial, de que las escuelas son las que más contribuyen a perpetuar las diferencias entre las clases sociales al influir resultados no-cognoscitivos más en el Tercer Mundo que en países tecnológicamente avanzados $^{44}$.

Finalmente, sin embargo, la posición de Harris falla en el punto donde el neo-marxismo es más vulnerable; su concepto de la falsa conciencia y el interrogante de cómo manejarlo. Si el proletariado en las sociedades capitalistas es susceptible a distorsiones de la realidad social, y si las escuelas sirven de intereses de la clase dominante perpetuando la falsa conciencia, ¿cómo se puede lograr el crecimiento en la conciencia revolucionaria? Muchos neo-marxistas, tales como Lukacs, han adoptado el concepto] leninista de que es el partido de vanguardia y no el proletariado "el que constituye el compendio histórico de la encarnación activa de la conciencia de las clases" y que por lo tanto es el que debe guiar la transición hacia el socialismo. Por el hecho de estar sumergido en los afanes de la necesidad económica, el proletariado es incapaz de elevarse como una clase hasta un estado de conciencia revolucionaria. Por otra parte, el mantener una distancia creativa entre sí y las masas ideológicamente encarceladas, el partido es capaz de construir una idea mundial políticamente coherente partiendo de los sentimientos rudimentarios que luchan por expresarse dentro del proletariado. El partido se convierte, en efecto, en la "objetivación" de la voluntad propia del proletariado, por mucho que los trabajadores no lo puedan reconocer. Este razonamiento está sólo a un paso de la conclusión de que la existencia misma del partido es una prueba tangible de su infalibilidad $^{45}$.

Es comprensible que los neo-marxistas, tales como Harris, que se centran en el papel de la educación, tiendan a evitar discusiones sobre cómo lograr una conciencia revolucionaria bajo el capitalismo, cuando instituciones, tales como las escuelas, controlan los conocimientos. Ellos parecen ser tácitamente sensibles a lo que Berger llama "arrogancia epistemológica" para describir cualquier proceso a través del cual, algunos individuos, debido a su mayor conciencia putativa, ayudan a redimir a las masas del dominio capitalista ${ }^{46}$. Sin embargo, los neo-marxistas son incapaces de conciliar la condición de dominación con una realidad que excluye la "desmistificación" por parte de aquellos que están dominados ${ }^{47}$. De no existir dicha conciliación, la posición neo-marxista permanecerá desesperadamente impositiva; por implicación, son los neo-marxistas

\footnotetext{
43 S Heyneman y W. Loxley, "The Impact of Primary School Quality on Academic Achievement across Twenty-Nine High and Low Income Countries" (Ponencia presentada en la reunión de la Asociación Sociológica Americana, Toronto, Agosto, 1981).

${ }^{44}$ Los teoristas Marxistas del sistema mundial relacionan los eventos educativos con los trabajos de un orden económico internacional para explicar por qué la expansión y reforma de la escolaridad sirve, con frecuencia, para perpetuar los sistemas existentes de estratificación. Sin embargo, análisis recientes han cuestionado seriamente las suposiciones y razonamiento histórico que han dado origen a la teoría marxista del sistema mundial (vease v.g. Chirot (No. 24 anterior). Cardoso y Faletto inclusive reivindican que la teoría de dependencia, corolaria marxista a la teoría del sistema mundial, ha muerto (véase F.H. Cardoso y E. Faletto, Dependency and Development in Latín America (Berkeley: Imprenta de la Universidad de California, 1979); véase también Mary Jean Bowman, análisis de Martin Carnoy, Education as Cultural Imperialism, Economic Development and Cultural Change 24 (Julio, 1976): 833-40). Sin embargo, no todos los análisis del sistema mundial son marxistas. En particular, los hallazgos de Meyer, Ramírez; Rubinson y Boli- Bennett se oponen a la afirmación marxista de que la expansión educacional ha contribuido a mantener la jerarquía del estado existente y el uso funcionalista de la modernización para explicar el crecimiento educacional (John W. Mayer, Francisco O. Ramírez, Richard Rubinson, y John Boli-Bennett, "The World Educational Revolution, 1950-1970", Sociology of Education 50 (Otoño de 1977): 242-58; véase también John W. Meyer y Michael T. Hannan, eds., National Development and the World System (Chicago: Imprenta de la Universidad de Chicago, 1979): y Francisco O. Ramírez y John Boli-Bennett, "Global Patterns of Educational Institutionalization", en Comparative Education, ed. Philip G. Altbach, Robert F. Arnove, y Gail P. Kelly (Nueva York: Macmillan, 1982), págs. 15-38).

45 Lukacs, Págs. 42 y 327; véase también Frank Parkin, Marxism and Class Theory: A Bourgeois Critique (Nueva York: Imprenta de la Universidad de Columbia, 1979), págs. 145-55.

46 Peter L. Berger, Pyramides of Sacrifice: Political Ethics and Social Change (Nueva York: Basic,1974), págs. 19 y 114.

${ }^{47}$ Para una discusión de ese punto véase Erwin H. Epstein, "The Social Control Thesis and Educational Reform in Dependent Nations", Theory and Society 5 (1978): 255-76.
} 
quienes se consideran como la vanguardia para guiar a las masas a un nuevo nivel de conciencia.

Existe una última forma para probar la virtud relativa de las ideas competitivas utilizando el criterio de Harris de servir igualmente a todos los intereses sociales, económicos y políticos. Esta forma es examinar los resultados no solamente en las sociedades capitalistas sino también en las sociedades socialistas, que es algo que Harris omitió. En vista de la evidencia disponible parecería que a las escuelas en los países de estados socialistas no les ha ido mucho mejor y quizás han respondido peor a la prueba que aquellas de los países de estados capitalistas. El hecho de que existen desigualdades considerables en los países socialistas ha estado bien documentado. Varios estudios han demostrado que las bonificaciones de pagos informales, las raciones especiales, el acceso privilegiado a tiendas que venden mercancías escasas a bajo precio, la provisión de casas campestres, el acceso exclusivo a puntos de veraneo y a hospitales y atención médica superior, así como el derecho a mejor alojamiento y a viajes al extranjero han creado notorias disparidades socioeconómicas entre los privilegiados y las masas en dichas sociedades ${ }^{48}$. Parkin ha observado que a medida que los países de Europa Oriental han respondido a las ineficiencias económicas adoptando estrategias incentivas, han experimentado un patrón claramente discernible de una desigualdad cada vez mayor. Además, el récord de los regímenes comunistas para proteger los intereses de todos los grupos durante la transformación de la estructura de remuneración de las antiguas economías capitalistas ha sido deficiente. Dondequiera que el partido comunista ha subido al poder ha establecido un sistema político unitario donde a la antigua burguesía se le ha negado el derecho de oponerse al cambio social, y donde los ciudadanos han sido objeto de tremendos abusos a sus derechos constitucionales ${ }^{49}$, las escuelas, desde luego, no han quedado exentas de estas demostraciones de inequidad; las investigaciones han confirmado que los niños nacidos en las clases socioeconómicas superiores tiene mayores posibilidades que los demás de alcanzar un alto nivel de educación ${ }^{50}$ - Más aún, a los judíos y a algunas otras minorías en la Unión Soviética se les ha privado de igualdad de oportunidades para una educación más avanzada y se les ha suprimido la instrucción religiosa ${ }^{51}$ - Hasta tanto que Harris y otros eruditos neo-marxistas puedan demostrar que su prueba sobre la virtud de un sistema teórico no es parcializada, parecerá injustificada su idea crítica del positivismo y la educación en las democracias liberales.

En resumen, encontramos que mientras que el neopositivismo busca estar libre de valores y ser objetivo, el neomarxismo pretende solamente ser objetivo ${ }^{52}$. En otras palabras, el neomarxismo admite una ausencia de desprendimiento en su perspectiva, pero sostiene que su concepto de realidad social es objetivo puesto que la objetividad refleja la verdad relativa.

\footnotetext{
${ }^{48}$ David Lane, The End of Inequality? Stratification under State Socialism (Baltimore: Penguin,1971); Mervin Matthews, Class and Society in Soviet Russia (Nueva York: Walker, 1972); Seymour Martin Lipset y Richard B. Dobson, "Social Stratification and Sociology in the Soviet Union”, Survey, No. 19 (Verano 1973), Págs. 114-85; Murray Yanowítch, Social and Economic Inequality in the Soviet Unión: Six Studies (White Plains, N.Y.: Sharpe, 1977); y Walter D. Connor, Socialism, Politics, and Equality: Hierarchy and Change in Eastern Europe and the U.S.S.R. (Nueva York: Imprenta de la Universidad de Colombia, 1979).

${ }^{49}$ Frank Parkin, Class Inequality and Political Order (Nueva York: Praeger, 1971).

${ }^{50}$ Murray Yonowitch y Norton Dodge, "Social Class and Education: Soviet Findings and Reactions", Comparative Education Review 12 (Octubre 1968): 248-67;Richard B. Dobson, "Mobility and Stratification in the Soviet Union", Annual Review of Sociology 3 (1977): 297-329; y Richard B. Dobson y Michael Swafford, "The Educational Attainment Procese ín the Soviet Union: A. Case Study", Comparative Education Review 24 (Junio 1980): 252-69.

${ }^{51}$ Erwin H.Epstein, "Ideological Factors in Soviet Educational Policy toward Jews", Education and Urban Society 10 (Febrero 1978): 223-54.

${ }^{52}$ Véase Michael Harrington, The Twiligth of Capitalism (Nueva York: Simon \& Schuster, 1976). 
Sin embargo, el neo-relativismo — cuyas suposiciones examinaré ahora- pretende solamente ser libre de valores. Profesa el desprendimiento y aduce que no hay ningún concepto particular de la realidad que sea más o menos verdadero que cualquier otro.

\section{La inclinación ideológica del neo-relativismo}

Junto con King, Brian Holmes es sin duda el neo-relativista mejor conocido en la educación comparada ${ }^{53}$. El enfoque del "problema de Holmes" fue incitado por el surgimiento de la relatividad en las ciencias naturales que presenta un reto al concepto de medición absoluta y a la validez incondicional de las leyes generales. Holmes sostiene que los científicos sociales se han demorado en reconocer el significado lógico de la relatividad para la teoría e investigación social y para la necesidad de una revolución paradigmática. Así como la relatividad proporcionó un motivo para cuestionar la validez lógica de los conceptos tradicionales de los absolutistas como masa, fuerza y demás, en el mundo físico, también debería poner a prueba la idea de que las leyes eternas fundamentales constituyen la base de todo comportamiento y desarrollo social, idea ésta que conforma los cimientos de la investigación social más contemporánea. La teoría social no debería estar formada por leyes eterna o infalibles, sino por una búsqueda de generalizaciones contextuales donde el comportamiento se considera regido por condiciones específicas espacio-temporales, lingüísticas y sociosicológicas dentro de circunstancias variables. Como la búsqueda de las leyes absolutas es inútil, la investigación "pura" no se justifica y representa una pérdida de tiempo y de recursos. Por el contrario las ciencias sociales, y en particular la educación comparada, deben responder a los problemas prácticos y a la necesidad de aplicación. La técnica social poco sistemática orientada a las políticas y con énfasis en objetivos modestos dentro del contexto de condiciones iniciales específicas y de circunstancias nacionales exclusivas, debería guiar la investigación comparada. La investigación no se debería iniciar con la recopilación de datos sino con la identificación y el análisis cuidadoso de un problema práctico discreto $^{54}$.

El método de Holmes representa una refutación del punto de vista positivista de que si se conocieren todos los factores que dan lugar a un comportamiento social particular, una manifestación multivariable explicaría dicho comportamiento dondequiera y cuandoquiera que se presentase. Pero también es un repudio al determinismo marxiano la creencia de que ciertas fuerzas económicas moldean inexorablemente la historia. Más que en una búsqueda de regularidades universales en la naturaleza y en la historia, Holmes considera que la investigación social comparativa debe estar guiada por un deseo de descubrir la singularidad de las naciones y sociedades, y propone la adopción del concepto Weberiano de interpretaciones normativas ideales-típicas como modelos contra los cuales examinar estructuras particulares y relaciones sociales. Tales interpretaciones, en la medida en que proporcionen coherencia a la multiplicidad de creencias que existen en la sociedad, y proporcionen indicios a los estados mentales colectivos y a la acción social, constituirán puntos de partida adecuados para la investigación. El uso propuesto de modelos normativos ideales-típicos no constituye un rompimiento abrupto con la teoría anterior sobre educación comparada; se pueden encontrar términos análogos en las ideas de relativistas clásicos tales como Michael Sadler y Vernon Mallinson, quienes pensaban respectivamente que una nación personificaba a un "espíritu viviente" o a un personaje

\footnotetext{
${ }^{53}$ Por mucho que King y Holmes riñesen sobre sus mutuas diferencias epistemológicas, ambos fueron estudiantes de Karl Popper y están mucho dentro de la tradición neo-relativista Popperiana (véase Brian Holmes, Problems in Education: A Comparative Approach (Londres: Routledge \& Kegan Paul, 1965), Pág. 53; Edmund J. King, Comparative Studies and Educational Decision (Nueva Cork: Bobbs-Merrill, 1968), Págs. 53-54; Brian Holmes, Comparative Education: Some Considerations of Method (Londres: Allen \& Urwin, 1981), pags. 70-71, y "Models In Comparative Education”, Compare 11 (1981): 155-61).

${ }^{54}$ Holmes, Comparative Educatlon: Sorne Consklerationa of Method.
} 
nacional. Los modelos ideales-típicos se centran más, sin embargo, en objetivos generales y teorías relacionadas con el hombre, la sociedad y el conocimiento, que en fuerzas inmanentes e intangibles. Holmes sostiene que los objetivos, teorías y estados mentales son componentes importantes de las condiciones iniciales específicas asociadas con el "problema" hacia el que se debe dirigir la atención del investigador.

Varios neo-relativistas han tratado de mostrar que a las estrategias educativas les falta viabilidad universal. Ocasionalmente ellos siguen a Piaget al hacer énfasis en la diferente perspectiva de cada organismo individual y en su diferente adaptación al ambiente. Algunos han sido inspirados por modelos etnometodológicos, fenomenológicos o simbólicos interaccionistas, con un énfasis en la interpretación social de la realidad y en el desarrollo del significado a través de la interacción. Clignet, por ejemplo, ha sugerido que lo que sucede en las escuelas es producto del uso que hacen profesores y estudiantes de mecanismos de adaptación diferentes e incompatibles; la adaptación de cada individuo varía con el perfil normativo y sociosicológico de la situación de cada aula ${ }^{55}$. Por consiguiente, ninguna ley que pretenda explicar las interacciones interpersonales se puede aplicar válidamente a la práctica educacional. Schrag sostiene que los aportes de la sicología a la ciencia y a la epistemología tienen poca utilidad práctica en la reforma y elaboración de políticas educativas, y que inclusive nuestro sentido común, comprensión preteórica del comportamiento humano, es una mejor guía en la práctica que la teoría sicológica. Popper lo expresó sucintamente cuando dijo: "Yo sugiero que lo que deberíamos hacer es renunciar a la idea de fuentes fundamentales de conocimiento, y admitir que todo el conocimiento es humano; que está mezclado con nuestros errores, prejuicios, sueños y esperanzas; que todo lo que podemos hacer es buscar a tientas la verdad aun cuando esté más allá de nuestro alcance ${ }^{56}$. Debemos admitir que nuestra búsqueda está a veces inspirada, pero debemos estar en guardia contra la creencia, por muy arraigada que esté, de que nuestra inspiración conlleva cualquier autoridad"57.

De las tres corrientes principales en la educación comparada, superficialmente el neorelativismo parece la menos dada a la ideología. Después de todo sostiene que todas las fuentes de conocimiento - ya sea comprendidas en el determinismo marxista o en las regularidades palpables buscadas por los positivistas - carecen de autoridad. Sin embargo, tanto los marxistas como los positivistas tendrían razón al aducir que por muy poco parcializado y libre de valores partidistas que parezca el relativismo, sus efectos son sin duda ideológicos. Esto es más evidente desde el punto de vista marxista, ya que cualquier posición que profese que ninguna posición tiene autoridad moral, tenderá a dejar libre el reto a la ideología dominante, que desde luego, con frecuencia resulta ser el capitalismo.

Más problemática pero quizás más convincente, sin embargo, es la crítica positivista que consta de dos componentes. El primero se aplica al método de solidaridad imaginativa de los relativistas, o sea, el método de comprender el comportamiento identificándose con los motivos y puntos de vista de los demás. Aquí hay un sofisma, por cuanto una comprensión del comportamiento lograda a través de un método tal nunca se podrá utilizar para explicar dicho comportamiento; la identificación con los motivos e ideas de los demás no constituye evidencia válida de una explicación, porque no se puede corroborar. Por una parte, cuando pensamos que nos hemos identificado con otros, es

\footnotetext{
${ }^{55}$ Remi Clignet, "The Double Natural History of Educational Interactions: Implications for Educational Reforms", Comparative Educatlon Review 25 (Octubre 1981): 330-52; véase también M. Mulkay, Science and the Sociology of Knowledge (Londres: Allen \& Unwin 1979).

${ }^{56}$ Francis Schrag, "Knowmg and Doing", American Journal of Education 89 (Mayo 1981): 253-82; véase también D.C. Philips,

"Toward an Evaluation of the Experiment in Educational Context", Educational Researcher 10 (Junio /Julio 1981): 13-20.

${ }^{57}$ Karl Popper, Conjetures and Refutations (Nueva York: Harper Torchbooks, 1968), págs. 29-30.
} 
posible que solamente les hayamos impuesto a los demás nuestros propios sentimientos, por mucho que podamos pensar que captamos las circunstancias contextuales sicosociales correspondientes. Por otra parte, inclusive si lográramos proyectamos en parte dentro de la mente de otras personas, ver las cosas exactamente en la forma en que ellas lo hacen sería compartir sus autodecepciones. Como lo expresa Frankel, "si realmente creyésemos que sólo podemos probar la verdad de una teoría acerca del comportamiento humano adoptando la actitud de los seres humanos de los que estamos hablando, tendríamos que recurrir a los paranoicos para verificar nuestras teorías sobre la paranoia" ${ }^{58}$.

El segundo componente de la crítica positivista se centra en la existencia de ciertas exigencias permanentes de naturaleza humana y en ciertas necesidades inmodificables de la sociedad humana que rigen los efectos que tiene una idea en la historia. Parece existir una necesidad universal e intangible de creer que lo que uno hace es parte de un designio eterno y que no todos nuestros logros y esperanzas están destinados a ser absorbidos por el tiempo ${ }^{59}$. Las necesidades y exigencias humanas dan origen $r$ respuestas similarmente fundamentales. Vemos, por lo tanto, que hay clases de naciones que muestran síndromes comunes de características históricas, culturales y sociales que no pueden explicarse por contextos sicosociales exclusivos ni por patrones ideales-típicos normativos compartidos. Las naciones y estados modernos muestran muchos puntos institucionales en común: tienen legislaturas, sistemas administrativos públicos, ejércitos y grupos de interés. Los arreglos institucionales de estructura similar sugieren que existen ciertos nexos comunes que no se pueden probar adecuadamente si cada sociedad se examina como una entidad única. El tipo de investigación ideográfica adelantada por los neo-relativistas puede ser de valor al proporcionar ideas acerca de la naturaleza de la educación bajo circunstancias específicas y puede informar a la política, pero no es probable que sea efectiva para desvincular sistemáticamente los factores asociados con la educación en una situación cultural específica, de los factores ajenos. El aspecto más preocupante del relativismo es, sin embargo, que tampoco está libre de ideología. Sugerir que cada evento humano debe ser juzgado desde la perspectiva única de los participantes es, en resumen un ideal que implica un prejuicio. Consideremos el análisis convincente de Frankel.

De hecho, al final existe una paradoja comprehensiva sobre el concepto de que todas las ideas sobre los asuntos humanos son verdaderas solamente desde el punto de vista de una cultura o clase social particular. Esta afirmación es de por sí una idea sobre los asuntos humanos. Si al igual que todas las demás ideas, fuere una doctrina que es verdadera para algunas personas pero falsa para otras, no hay un motivo por el cual las personas que tienen puntos de vista diferentes le deban prestar atención alguna. Si, por otra parte, no es limitada en su validez, entonces constituye una excepción en la misma generalización que promulga. Es un ejemplo de una idea cuya verdad trasciende las circunstancias históricas en que se promulga. $Y$ si existe tal idea, sería arbitrario sugerir que no puedan existir otras ${ }^{60}$.

Si, de hecho, el concepto de relatividad no está limitado en su validez, y si su verdad trasciende las circunstancias históricas en que se promulgó, entonces parece lógico que ciertos individuos -aquellos entrenados para evaluar eventos en términos de sus circunstancias sicosociales exclusivas, o sea, los relativistas- deben ser los llamados a exponer sistemáticamente la parcialidad de todas las ideas. Tal formulación es Platónica

\footnotetext{
${ }^{58}$ Charles Frankel, The Case for Mordern Man (Boston: Beacon, 1956), pég. 130.

${ }^{59}$ Véase Jacques Maritain, Scholasticism and Politics, trad, M.J. Adler (Londres: Bies, 1940).

${ }^{60}$ Frankel, Págs. 135-36. 
en sus implicaciones; invita al establecimiento de una oligarquía de intelectuales para ser los guardianes, si no de la "verdad", por lo menos de las normas del procedimiento correcto $^{61}$.

\section{Conclusión}

Ya que he criticado a todo el mundo, ¿cómo seguir?

Una cosa que no haré será sugerir la superioridad o inferioridad absoluta de una u otra de las tres corrientes importantes en la educación comparada, ya que esto sería contrario a mi propósito. Lo que he tratado de hacer principalmente es mostrar qué tan inseparable es cada corriente desde el punto de vista ideológico, y yo quisiera discutir un cambio fundamental en la forma en que conceptualizamos el desarrollo en nuestro campo.

La noción convencional del desarrollo de nuestro campo fue más firmemente establecida por Noah y Eckstein, quienes identificaron cinco etapas evolucionarias: 1) narraciones de viajeros, 2) empréstitos educacionales, 3) cooperación educativa internacional, 4) identificación de las fuerzas y factores que conforman los sistemas educativos nacionales, y 5) explicación de la ciencia social. Aun cuando Noah y Eckstein admiten que estas etapas están lejos de ser discretas en tiempo, su modelo es claramente evolutivo, y como tal injustificable y engañoso. Debido a su utilización de la palabra "período" para describir etapas, a su frecuente alusión a circunstancias históricas asociadas con métodos particulares, y a su énfasis en el desarrollo con un propósito determinado, es evidente que ellos ven cada etapa como una ocurrencia clara y precisa dentro de una mayor progresión evolucionaria hacia lograr claridad en la comprensión de las relaciones entre la escuela y la sociedad.

Consideremos el primer propósito: revelar "el surgimiento gradual e inseguro de un sistema científico social empíricamente basado en educación comparada, cuya historia comienza con una narración simple, a veces ingenua, pero con frecuencia sagaz, y termina, en el presente, con la aplicación de los métodos sofisticados que se están empleando actualmente en las ciencias sociales". $Y$, segundo, consideremos su reivindicación de que su modelo evolutivo, "por muy indefinido que sea, proporciona un marco conveniente y poco forzado dentro del cual se puede revisar el desarrollo del campo"62. Yo sostengo, sin embargo, que el desarrollo evolutivo se puede atribuir a discretas corrientes epistemológicas, pero no a la educación comparada en general, y que el modelo evolutivo no se puede entender como un marco poco forzado dentro del cual se pueda considerar el desarrollo del campo.

El modelo evolutivo es inadecuado porque viola tres principios de interpretación teórica: compatibilidad interna, exclusividad mutua, e inclusividad ${ }^{63}$. Consideremos primero los principios conexos de compatibilidad interna y de la exclusividad mutua.

\footnotetext{
${ }^{61}$ Esto es esencialmente lo que propuso Mannheim (véase Karl Mannheim, Ideology and Utopia (Nueva York: Harcourt, Brace, 1951)).

${ }^{62} 65$ Noah y Eckstein (N. 1 anterior), Pág. 4.

${ }^{63}$ Estos principios corresponden a grandes rasgos a criterios particulares para evaluar las teorías en la literatura de la filosofía de la ciencia. La compatibilidad interna y la exclusividad mutua son temas análogos de compatibilidad lógica, y la inclusividad es similar al alcance de una teoría (véase Philipp G. Frank, The Validation of Scientific Theories (Boston: Beacon, 1956), Págs. 3-36; y Jack Gibbs, Sociológica Theory Construction (Hinsdale, III.; Dryden, 1972), Págs. 58-70). Para una explicación de cómo el criterio de la compatibilidad lógica se puede aplicar a asestar un "golpe de muerte" a una teoría, véase James D. Carney y Richard K. Scheer, Fundamentals of Logic (Nueva York: Macmillan 1964), paga. 367.68. Una variedad de disciplinas han violado el principio de la inclusividad. Por ejemplo, los primeros años de la sociología Americana estuvieron marcados por estrechas fronteras ideológicas que restringieron las consideraciones razonables del pensamiento marxiano (véase Duskey Lee Smith, "Sociology and the Rise of Corporate Capitalism", en The Sociology of Sociology, ed. Larry Reynolds y Janice Reynolds (Nueva York: McKay, 1970), págs. 6881; Herman Schwendinger y Julia Schwendinger, The Sociologists of the Chair (Nueva York: Basic, 1974); y Patrick J. Gurney, 
Un modelo teórico dado se basa en la estabilidad de sus categorías, las que en el caso del modelo de Noah y Eckstein, son etapas de desarrollo.

Para que una categoría sea estable, debe contener propiedades que en su consistencia interna se puedan distinguir razonablemente de las propiedades de otras categorías. En el modelo evolutivo de Noah y Eckstein, las propiedades de cualquier etapa específica de desarrollo, salvo por el tiempo mismo, son prácticamente imposibles de distinguir entre sí. Por ejemplo, Noah y Eckstein caracterizan los escritos de Marc-Antoine Jullien de principios del siglo XIX, como "el mejor ejemplo" del trabajo adelantado durante la etapa de empréstito educacional.

Sin embargo, su descripción del aporte de Jullien pone de manifiesto que tenía poco en común con los más prominentes de sus contemporáneos. En efecto, Jullien estaba interesado en observar irregularidades en la práctica educacional a través de la recolección de datos a niveles nacionales, actividad que lo identifica más precisamente como un positivista que como un prestatario educacional. Es interesante que Noah y Eckstein demuestren su inclinación ideológica como positivistas describiendo el trabajo de Jullien, no como el precursor de una corriente particular, la del positivismo, dentro de la educación comparada moderna como un campo general, que no lo es. Por contraste, describen el "préstamo" del compatriota y contemporáneo de Jullien, Víctor Cousin, en términos menos favorables orientados hacia el vigor de la cultura francesa y hacia "la indestructible unidad de nuestro carácter nacional", revelando así las tendencias decididamente relativistas de Cousin ${ }^{64}$.

Colocar dentro de la misma categoría a dos individuos como Jullien y Cousin, que estaban tan mutuamente opuestos desde los puntos de vista epistemológicos e ideológicos, como lo hacen Noah y Eckstein, viola el principio de compatibilidad interna y extiende la imaginación más allá de la razón. Noah y Eckstein luego prosiguen a describir el trabajo de Michael Sadler a comienzo del siglo XX como un puente en la etapa de la recopilación de datos "de orden enciclopédico y algo indiscriminado" con el período de fuerzas y factores ${ }^{65}$. En realidad, la preocupación de Sadler por la educación como "una expresión de la vida y carácter nacional", a pesar de sus métodos científicos bastante avanzados para el período, revela su afinidad con Cousin en vez de con Jullien, y con los relativistas anteriores y posteriores a su época. Ignorando la influencia insignificante de Sadler sobre los no-relativistas y glorificando sus contribuciones al campo en general, Noah y Eckstein y otros eruditos en educación comparada persistentemente violan el principio de exclusividad mutua. Kazamias y Massialas, en un arranque de hipérbole, llegan hasta argumentar que los "principios Sadlenianos han llegado a ser la piedra angular de la orientación teórica de la educación comparada del siglo XX"66.

Finalmente, la violación de Noah y de Eckstein del principio de inclusividad se demuestra por su total negligencia del sistema marxista. En ninguna parte su análisis da cabida al marxismo o a la crítica radical en la educación comparada como parte de cualquier etapa en el desarrollo del campo.

Otra prueba para juzgar la idoneidad de un sistema para estudiar el desarrollo de un campo radica en su capacidad para discernir la vida acumulativa del campo. Como lo he

\footnotetext{
"Histoncal Origins of Ideological Denial: The Case of Marx tu American Sociology", American Sociologist 16 (Agosto 1981): 196201).

${ }^{64}$ Noah y Eckstein (N. 1 anterior), Págs. 14-33.

${ }^{65}$ ibid págs. $40-57$ y 65 .

${ }^{66}$ Andreas M. Kazamias y Byron G. Massialas, Tradition and Change in Education: A Comparative Study (Englewood Cliffs, N.J.: Prentice-Hall, 1965), pag. 3.
} 
mostrado, el modelo evolutivo falla en su último análisis porque intenta considerar las corrientes principales de la educación comparada dentro del mismo universo de disertación, cuando en efecto estas orientaciones proceden de teorías de la verdad filosóficamente incompatibles e ideológicamente irreconciliables que las mantienen encerradas en un nicho a cada una. Sin embargo, por mucho que podamos lamentar la superioridad farisaica que cada una de estas corrientes proclama contra las otras, y lo que esto pueda implicar en relación con el logro de unidad para nuestro campo, cada una de ellas muestra una vida propia acumulativa y fuerte y una capacidad comprobada para atraer discípulos que mantengan la fe. El campo en general no puede reivindicar tanto éxito El hecho de que exponentes de cada corriente estén renuentes a aceptar los métodos y hallazgos de las otras, significa que la acumulación de conocimiento no está tanto dentro del campo generalizado sino que está selectivamente repartida de acuerdo con la afinidad ideológica. Los neo-marxistas tienen muy poco que decir a los neopositivistas y a los neo-relativistas, y estos últimos tienen muy poco que decirle a los primeros y que comentarse mutuamente. La supervivencia definitiva del campo se debe más a la conveniencia pragmática de asociación -lo que podría llamarse un matrimonio de conveniencia - puesto que los números son pequeños y los recursos para apoyar las reuniones y las publicaciones son escasos, y al interés común en la comparación, cualquiera que sea su definición, que a las suposiciones epistemológicas comunes y a un universo de disertación compartida acerca de la educación.

La educación comparativa no ha evolucionado como un campo unitario sino como una unidad suelta de corrientes separadas aun cuando florecientes. Es extraño que a pesar de la adherencia de los eruditos a una u otra de estas corrientes incompatibles, muy pocos analistas han discernido sus incongruencias ideológicas, Paulston, quien fomenta un modelo paradigmático del desarrollo del campo, constituye una notable excepción. Desafortunadamente, aun cuando Paulston satisface los principios de compatibilidad interna y de exclusividad mutua, y por consiguiente propone un sistema que constituye un mejoramiento considerable sobre el modelo evolucionario, viola el principio de inclusividad al ignorar totalmente la tradición relativista. Y lo que es más importante, aun cuando alaba el papel de la ideología en la interpretación del paradigma sin llegar a hacer nada práctico al respecto, Paulston vicia su significado exigiendo un sistema común que especifique "generalizaciones que puedan someterse a prueba acerca de las condiciones necesarias y suficientes para esfuerzos de cambio "estructural y normativo" a gran escala, y que no esté encerrado por teorías funcionales o de conflicto sino que aproveche en forma selectiva y crítica cada orientación ${ }^{67}$. Lamentablemente las ideologías son menos dóciles a tales impulsos acomodaticios que lo que Paulston nos quiere hacer creer.

El peligro que la ideología presenta para nuestro campo no es tanto en términos de su simple existencia como en términos de nuestra tendencia a evitar su reconocimiento. Si en efecto la ideología es una parte inescapable de cualquier epistemología a la que nos suscribamos, podemos aprender a vivir con ella sólo admitiendo su existencia en nuestra propia escolaridad. Este acto de admisión y la aplicación de nuestras energías para tratar con la ideología en nuestro trabajo serviría dos propósitos vitales:

1) Nos haría más conscientes de la inclinación y de los valores que inspiran nuestros propios métodos, contribuyendo así a una escolaridad más informada; y

\footnotetext{
${ }^{67}$ Paulston (n. 4 anterior), Pág. 395. El sistema de Paulston incluye el paradigma de que comparte suposiciones en común con el neopositivismo y el paradigma de conflicto, cuyo término análogo más prominente es el neo-marxismo. 
2)Nos haría menos farisaicos acerca de la escolaridad de otros con diferentes epistemologías, ayudando así a evitar querellas mutuamente destructoras que podrían lacerar nuestro campo. Como la comparación involucra interacción entre culturas y formas de gobierno y sus diversas sensibilidades, y la educación se concentra en el segmento más impresionable de la sociedad, la naturaleza de la educación comparada es particularmente delicada y vulnerable a segmentaciones devastadoras. No es suficiente poder confiar en la naturaleza común de las actividades no académicas -la preparación de reuniones, la impresión de periódicos, la publicación de boletines informativos, el establecimiento de redes de comunicación, etc. - para poder superar nuestras diferencias filosóficas y mantener nuestro campo vivo. Debemos también trabajar escrupulosamente para entender esas diferencias y para respetar las suposiciones y creencias fundamentales de los otros, a pesar de las críticas que podamos tener. Hasta el día en que descubramos un mejor método de escolaridad esto es lo máximo que podemos esperar. Me vienen a la mente las palabras de George Orwell, quien escribió: "Sé que está de moda decir que la gran mayoría de la historia escrita no es más que una mentira. Estoy dispuesto a creer que gran parte de la historia es imprecisa y tergiversada, pero lo que es peculiar a nuestra época es renunciar a la idea de que la historia puede ser verazmente escrita"68. Lo que Orwell dijo de la historia puede también aplicarse a la educación comparada. Si hemos de evitar el peligro, debemos desempeñarnos mejor en el futuro de lo que nos hemos desempeñado en el pasado. Confío en que con sensibilidad hacia las conjeturas de los otros, con indulgencia para quienes disienten y con un reconocimiento saludable de la ideología que informa nuestro pensamiento, nos desempeñaremos mejor. Por mucho que contrapesen nuestras suposiciones epistemológicas, debemos res-guardarnos contra el ejercicio de nuestras respectivas creencias para no limitar el alcance de investigación de otros.

Nuestra vigilancia cosechará amplias recompensas en los nuevos senderos que se deben recorrer y en la madurez que le sigue a la comprensión mutua.

SUMARIO.- El autor expone las principales corrientes en la educación comparada (neo-marxismo, neo-positivismo, neo-relativismo) mostrando las relaciones de cada una de ellas con aspectos ideológicos y enfatizando en el hecho de la separación entre estos enfoques.

Concluye sobre la necesidad de reconocer la presencia de la ideología en el campo de la educación comparada para evitar querellas destructoras y lograr una mayor madurez en los análisis epistemológicos.

DESCRIPTORES.—Educación Comparada - Teoría de la Educación —Sociología Educacional.

\footnotetext{
${ }^{68}$ George Orwell, Such, Such Were The Joys (Nueva York: Harcourt, Brace, 1953), pág. 141.
} 